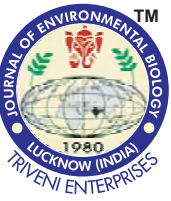

DOI : http://doi.org/10.22438/jeb/39/3/MRN-348

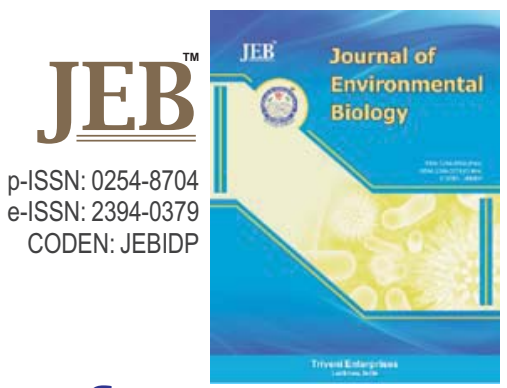

\title{
Physio-chemical properties and pigment changes in the pericarp of mango cultivars during storage and ripening
}

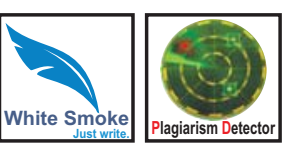

Authors Info

B. Killadi*, R. Chaurasia, D.K. Shukla and A. Dikshit

Division of Post Harvest Management, ICAR- Central Institute for Subtropical Horticulture, Lucknow -226 101, India

*Corresponding Author Email : bharatipal.pal@gmail.com

Key words

Carotenoids

Chlorophyll

Mango cultivars

Pericarp pigments

Publication Info

Paper received : 05.05.2016

Revised received : 18.01.2017

Re-revised received : 05.05.2017 Accepted : 07.09.2017

\begin{abstract}
\end{abstract}
Aim : The present investigation aimed at quantifying the changes of pericarp pigments and associated physio-chemical attributes in commercial cultivars of mango fruits during storage and ripening.

Methodology : Mango fruits of cv "Bombay Green", "Dashehari" and "Langra" were harvested at mature green stage and stored under ambient conditions $\left(30 \pm 2^{\circ} \mathrm{C}\right.$ and 85 to $90 \%$ R.H.). The fruits were periodically withdrawn at 2, 4, 6 and 8 days intervals to assess the pericarp chlorophylls, carotenoids and physicochemical attributes during storage and ripening.

Results : Total chlorophyll content in the proximal end of fruit pericarp decreased in cultivar 'Bombay Green' while total carotenoids increased from the day of harvest to $8^{\text {th }}$ day of storage, with no external colour change. In cultivar 'Dashehari', fruits had distinct yellow proximal end with decreased total chlorophyll (6.09

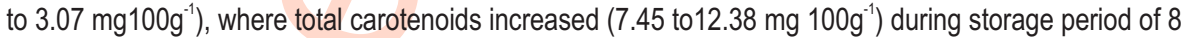
days. In cultivar 'Langra', similar trend was observed. The cumulative physiological loss in weight (CPLW) was maximum (16.22\%) in cultivar 'Bombay Green',(13.30\%) in cultivar 'Dashehari' and minimum(12.39\%) in cultivar 'Langra' on the $8^{\text {th }}$ day of storage under ambient conditions. The pulp total carotenoids content $\left(10.03 \mathrm{mg}^{100 \mathrm{~g}^{-1}}\right)$ in 'Bombay Green', $\left(7.36 \mathrm{mg}^{100 \mathrm{~g}^{-1}}\right)$ in 'Dashehari' and $\left(5.18 \mathrm{mg}^{100 \mathrm{~g}^{-1}}\right)$ in 'Langra'. The total antioxidant content were $\left(70.48 \mu_{\text {molesml }}{ }^{-1}\right)$ in cultivar 'Langra', $\left(70.39 \mu\right.$ molesm $\left.^{-1}\right)$ in 'Dashehari' and $\left(26.74 \mu\right.$ mole $\left.\mathrm{ml}^{-1}\right)$ in 'Bombay Green' on the $8^{\text {th }}$ day of storage.

Interpretation: The pigment changes in commercial cultivars of mango during storage and ripening were variety specific in conjunction with chlorophyll degradation and total carotenoids synthesis in pericarp and mesocarp.
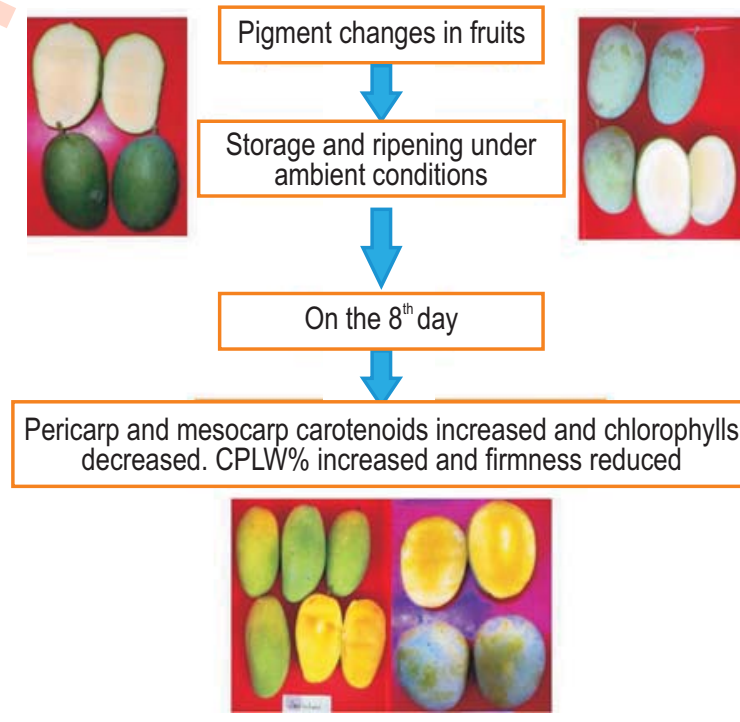


\section{Introduction}

Mango is economically important and popular fruit, due to its bright colour, sweet taste and luscious flavour. One of the reliable parameter to determine the maturity in mango is external colour change. Mango fruits during ripening synthesize carotenoids. Mesocarp of the fruit turns from cream to yellow to deep yellow or orange yellow due to carotenoids development during ripening and storage. Mango's characteristic pericarp and mesocarp colour development involves a progressive loss of chlorophyll in addition to an increase in carotenoids composition and content (Lizada, 1991). This indicates that transition of mango pericarp and mesocarp colour does not involve unmasking of carotenoids, but synthesis (Fennema, 1996). Change in carotenoids during ripening involves development of $\beta$-carotene, the concentration of which is highest in fully ripe fruits. Most commercial mango cultivars have distinct yellow mesocarp and pericarp with bright yellow to little or no pigmentation. At maturity, carotenoids are typically absent as the mesocarp is hard and cream in colour; while chlorophyll is restricted to the fruit surface. Mango has been studied for ascorbic acid (RoblesSanchez et al., 2009; Valente et al., 2011), carotenoids (Chen et al., 2004; Mercadante et al., 1997; Pott et al., 2003; VasquezCaicedo et al., 2005; Vasquez-Caicedo et al., 2007), antioxidant enzymes (Saxsena et al., 2014) and ripening (Singh et al., 2012), but data regarding the physio chemical attributes and its associated changes in the pericarp pigments changes of mango commercial cultivars of north India are limited. Therefore, the objective of this study was to quantify the physio-chemical attributes and associated pigments changes in the pericarp of commercial mango cultivars during storage and ripening .

\section{Materials and Methods}

Commercially important cultivars 'Bombay Green', 'Dashehari' and 'Langra' were selected based on early to late maturity for the purpose of study. Green mature fruits of mangoes were harvested with stalk of 8-10 mm and washed with water, surface dried, packed and stored under ambient conditions (34 $\pm 2^{\circ} \mathrm{C}$ and 85 to $90 \%$ R.H.). The observations on pigment changes and physio chemical parameters were recorded at an interval of $2,4,6$ and 8 days of storage. The fruit weight was recorded at the time of packaging, and subsequently at each withdrawal. The difference in weight was expressed as per cent weight loss. Firmness of the fruit was measured with the help of penetrometre ( $8 \mathrm{~mm}$ probe, USA) and expressed as $\mathrm{kg} \mathrm{cm}^{-2}$. Total soluble solids (TSS) was estimated with the help of a digital refractometer, model PAL-1 (Atago, Tokyo, Japan). Titratable acidity (TA) was estimated by taking five gram of sample diluted to $50 \mathrm{ml}$ of distilled water and titrated with $0.1 \mathrm{moll}^{-1} \mathrm{NaOH}$ solution and the results were expressed as per cent citric acid (Ranganna,2000).

Fruit pericarps were separated from the proximal/stem end, distal end and middle portion for estimation of total carotenoids and total chlorophyll contents. Two gram of sample was weighed accurately, and a small quantity of $(0.1$ to $0.2 \mathrm{~g})$ calcium or sodium carbonate acid washed sand was added. Acetone (85\%) was added 2 to 3 times, and grinded continously, and filtered. The filtrate was collected in a flask and the final volume made to $50 \mathrm{ml}$ with acetone (85\%). The optical density of samples were measured at $600 \mathrm{~nm}, 642.5 \mathrm{~nm}$ and $660 \mathrm{~nm}$ and

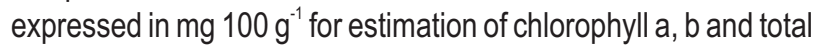
chlorophyll (Ranganna, 2000). Total carotenoids in the mesocarp was estimated by weighing $2 \mathrm{~g}$ sample in triplicate, extracted in 15 $\mathrm{ml}$ acetone thrice and filtered through cotton wool in a conical flask. Samples were extracted till colourless. Petroleum ether (15 $\mathrm{ml}$ ) was added to the extract and diluted with $2 \%(15 \mathrm{ml})$ sodium chloride solution. All the extracts were transferred in a separating funnel and washed with $10 \mathrm{ml}$ of $2 \%$ sodium chloride. The nonaqueous layer was extracted and collected in a $50 \mathrm{ml}$ volumetric flask and volume was made up with $3 \%$ acetone in petroleum ether and the optical density measured at $452 \mathrm{~nm}$ and expressed

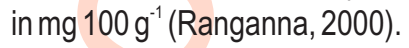

Ferric reducing antioxidant power (FRAP) assay was done by reducing ferric-tripyridyltriazine complex to its ferrous coloured form in the presence of antioxidants (Benzie and Strain, 1996). The FRAP consisted $2.5 \mathrm{ml}$ of a $10 \mathrm{~m} \mathrm{~mol}^{-1} \mathrm{TPTZ}(2,4,6$ tripyridy-s-triazine, Sigma) solution in $40 \mathrm{~m} \mathrm{moll}^{-1} \mathrm{HCL}$ plus $2.5 \mathrm{ml}$ of $20 \mathrm{~m} \mathrm{~mol} \mathrm{I}^{-1} \mathrm{FeCl}_{3}$ and $25 \mathrm{ml}^{\circ} 0.3 \mathrm{moll}^{-1}$ acetate buffer, $\mathrm{pH} 3.6$ and was prepared freshly and warmed at $37^{\circ} \mathrm{C}$. Aliquots of $40 \mu \mathrm{l}$ sample supernatant were mixed with $0.2 \mathrm{ml}$ distilled water and 1.8 $\mathrm{ml} \mathrm{FRAP} \mathrm{reagent} \mathrm{and} \mathrm{the} \mathrm{reaction} \mathrm{mixture} \mathrm{was} \mathrm{incubated} \mathrm{at} 37^{\circ} \mathrm{C}$ for $10 \mathrm{~min}$ and absorbance was measured at $593 \mathrm{~nm}$ by spectrophotometer. The standard solution used was $1 \mathrm{mmol} \mathrm{I}^{-1}$ $\mathrm{FeSO}_{4}$ and the final result was expressed as the concentration of antioxidants having a ferric reducing ability equivalent to that of $1 \mathrm{mmol}^{-1} \mathrm{FeSO}_{4}$. If the FRAP value measured was above the linear range of standard curve then adequate dilutions were made.

All the analysis was carried out in triplicates and the data recorded during the course of investigation were subjected to statistical analysis by SAS 9.3 and CD at 0.05 level.

\section{Results and Discussion}

The total chlorophyll content in the proximal end of the fruit varied significantly $(p \leq 0.5)$ among the varieties during the course of storage and ripening under ambient conditions (Fig. 1, 2 and 3). At proximal end of the fruit pericarp; total chlorophyll content decreased (6.01 to $2.44 \mathrm{mg}^{100 \mathrm{~g}^{-1}}$ ), chlorophyll 'a' content

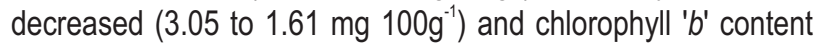

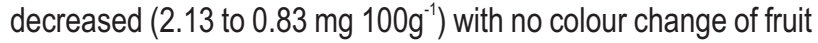
surface in cultivar 'Bombay Green' from the day of harvest to $8^{\text {th }}$ day of storage. In cultivar 'Dashehari', fruits had distinct yellow proximal end with decreased total chlorophyll (6.09 to $3.07 \mathrm{mg}$

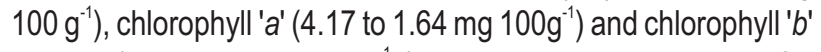

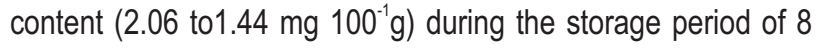


days. Cultivar 'Langra' had pale green in colour shoulders or proximal end with decreased total chlorophyll (4.15 to $3.44 \mathrm{mg}$

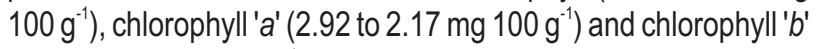

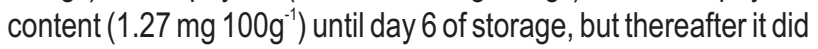
not change significantly. Similar decrease in total chlorophyll content, chlorophyll 'a' and chlorophyll ' $b$ ' content were observed in the middle and distal end of pericarp in all the three cultivars of mango. In cultivars 'Dashehari' and 'Langra', the middle portion of the fruit pericarp was pale green in colour. Significant differences in chlorophyll concentration were observed among the commercial cultivars studied, similar to avocado fruits (Katy et al., 2014). Cultivar 'Langra' mangoes, upon ripening, have a characteristic 'stay-green' character due to chlorophyll ' $b$ ' and pheophytin accumulation (Janave and Sharma, 2006). High temperature and humidity under ambient conditions results in enhanced biosynthesis process of chlorophyll degradation and an increase in carotenoid content (Dhemre and Waskar, 2004).
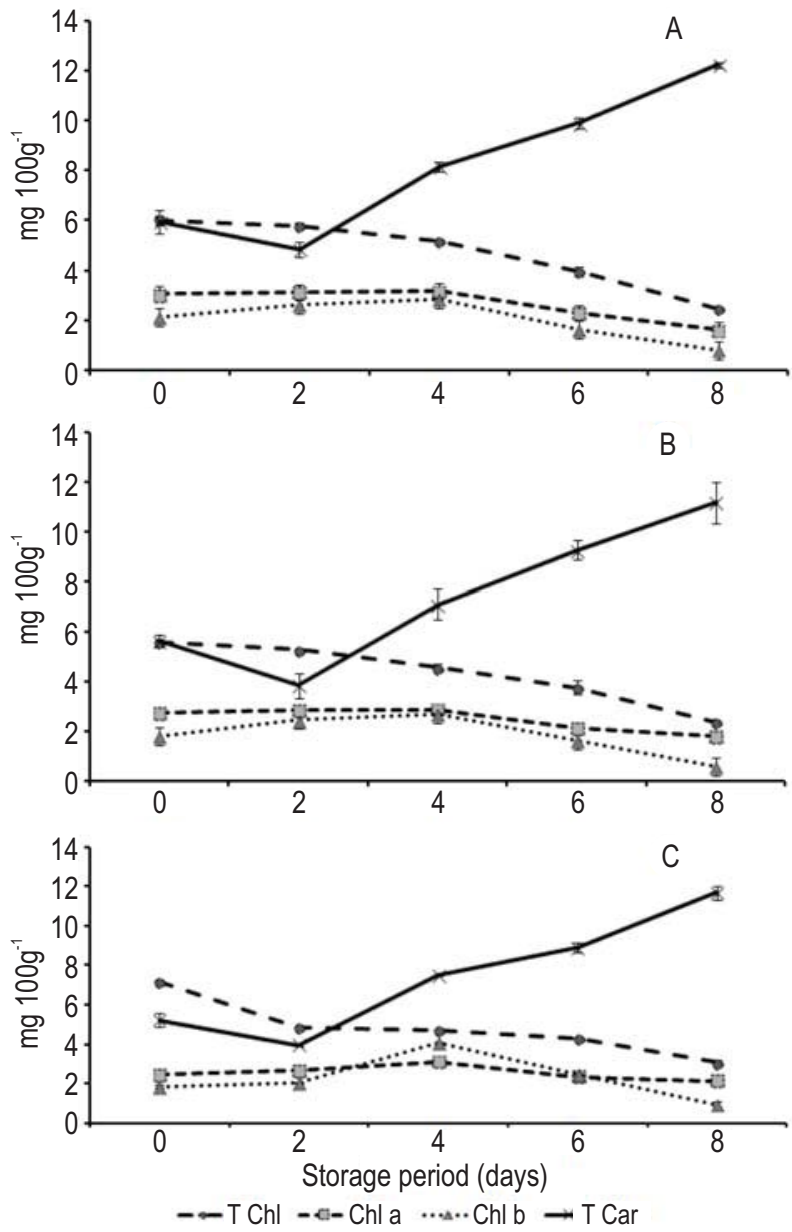

Fig. 1: Changes in chlorophyll 'a' (Chl a), 'b' (Chl b), total chlorophyll (T $\mathrm{Chl}$ ) and total carotenoids (T Car) of pericarp in cultivar 'Bombay Green' ('A' proximal end, 'B' middle portion and 'C' distal end) during storage and ripening of fruits
Significant variation $(p \leq 0.5)$ was observed in the total carotenoid content among the cultivars and between the proximal end, middle part and distal end of the pericarp in mango fruits (Fig.1,2 and 3.). In cultivar 'Bombay Green', the total carotenoid content increased (4.52 to $\left.12.39 \mathrm{mg} \mathrm{100}^{-1}\right)$, while it increased

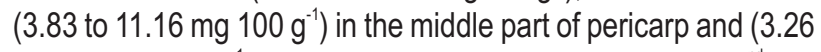

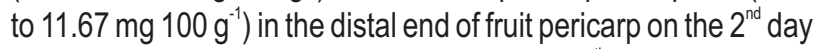
of storage and continued to increase up to $8^{\text {th }}$ day of storage. Though the pericarp carotenoids content increased, there was no change in colour of fruit cultivar 'Bombay Green'. Total carotenoids content of the proximal end in cultivar 'Dashehari' increased (5.05 to $12.22 \mathrm{mg}^{100 \mathrm{~g}^{-1}}$ ), the middle part increased

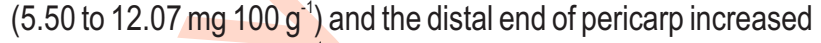

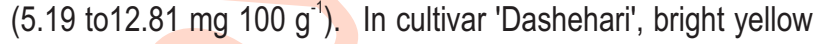
colour developed on the shoulders (proximal end), the middle part of fruit was light green in colour and the distal end was greenish in colour. In cultivar 'Langra', the total carotenoid content of the
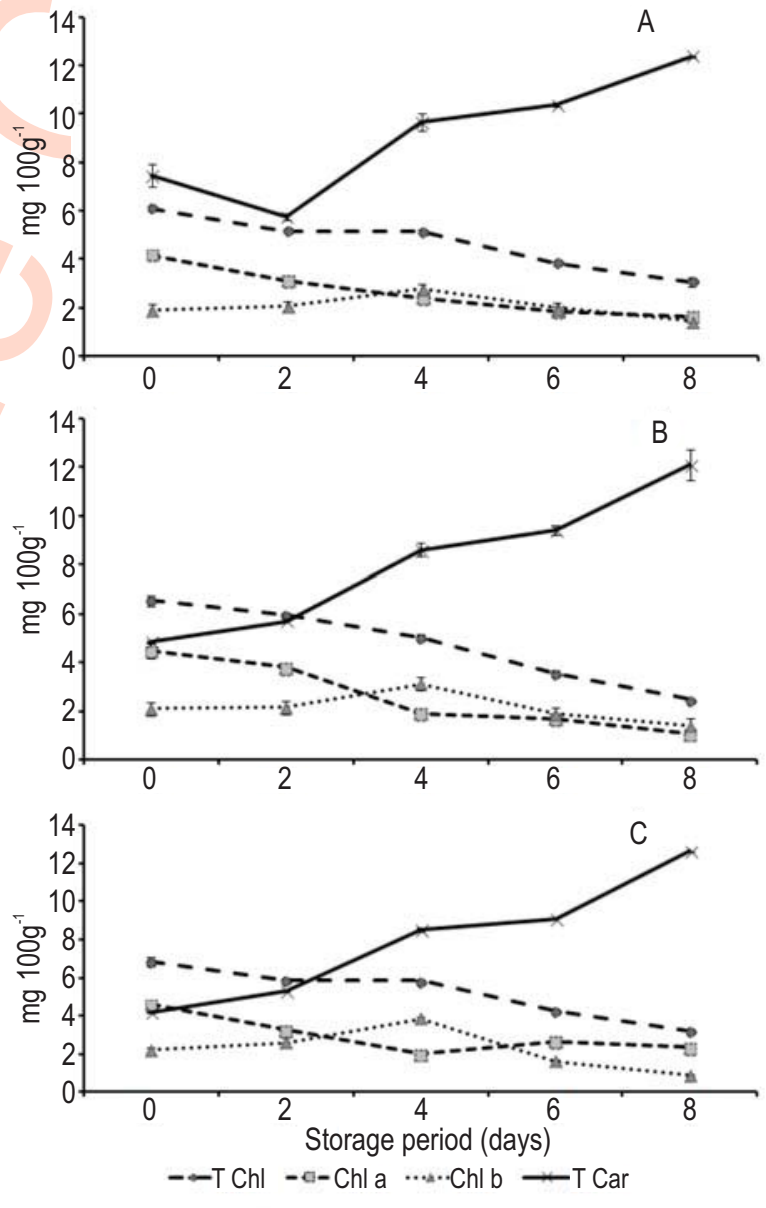

Fig. 2 : Changes in chlorophyll 'a' (Chl a), 'b' (Chl b), total chlorophyll (T $\mathrm{Chl}$ ) and total carotenoids ( $\mathrm{T}$ Car) of pericarp in cultivar 'Dashehari' ('A' proximal end, 'B' middle portion and 'C' distal end) during storage and ripening of fruits 

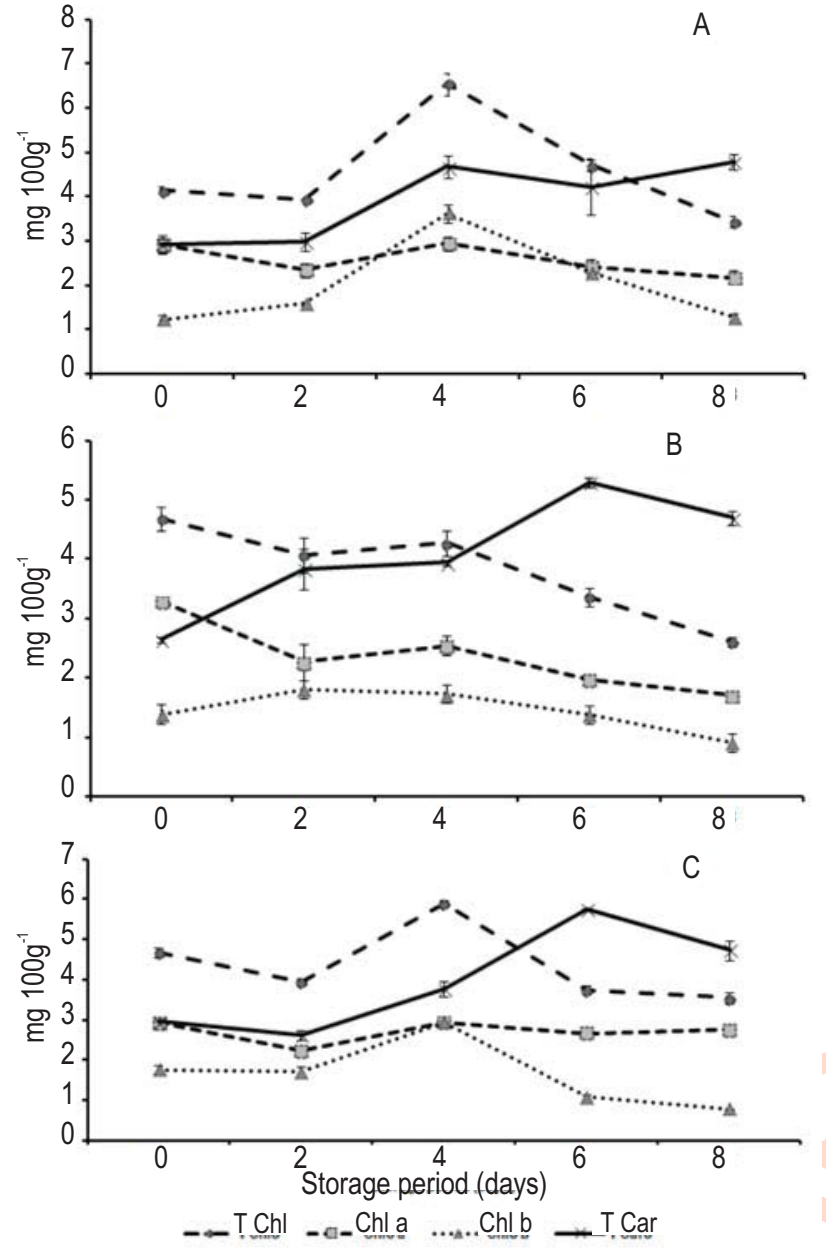

Fig. 3 : Changes in chlorophyll 'a' (Chl a), 'b' (Chl b), total chlorophyll (T $\mathrm{Chl}$ ) and total carotenoids (T Car) of pericarp in cultivar 'Langra'('A' proximal end, ' $\mathrm{B}$ ' middle portion and ' $\mathrm{C}$ ' distal end) during storage and ripening of fruits

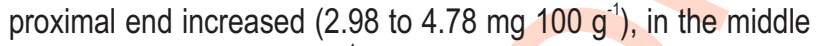

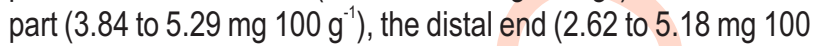
$\left.\mathrm{g}^{-1}\right)$ and overall the fruit was yellowish green in colour. The results of the present study for commercial cultivars of mangoes varied; the ripe fruits of cultivar 'Bombay Green' were green in colour, while cultivar 'Dashehari' had yellow pistil end with green distal end and cultivar 'Langra' fruits were greenish yellow in colour. Carotenoid content may be linked to fruit colour (Ahmed et al., 2002). Fruit colour changes due to "unmasking" of existing pigments (Wills et al., 1989). After the initial phase colour changes is primarily due to synthesis of carotenoids in avocado skin (Lancaster etal., 1997).

There was a significant difference $(p \leq 0.5)$ in the weight loss among the varieties and storage period (Fig.4.A.). The CPLW per cent increased with increased in storage period. On the $2^{\text {nd }}$ day of storage, there was a CPLW of $2.47,2.66$ and $1.75 \%$ in cultivar 'Bombay Green', 'Dashehari' and cultivar 'Langra', respectively. At the end of storage on $8^{\text {th }}$ day, there was an increase in CPLW cultivar 'Bombay Green' had 16.22, 'Dashehari' 13.30 and cultivar 'Langra' $12.39 \%$. On the $8^{\text {th }}$ day of storage cultivar, 'Bombay Green' exhibited highest CPLW coinciding with shrivelling of fruit surface compared to the fruits of 'Dashehari' and 'Langra'. The increase in CPLW may be due to evapotranspiration from the surface of fruits. Fruit transpiration varies significantly according to climactic conditions and characteristic of fruit that affects water balance. These findings are in concomitance with tomato (Leonadi et al., 1999). With increase in storage period firmness of the fruits decreased, it significantly varied $(p \leq 0.5)$ among the commercial cultivars and during storage and ripening (Fig.4.B.). The firmness of the fruits decreased at an increasing rate in cultivar 'Bombay Green' (12.17 to $5.98 \mathrm{Kg} \mathrm{cm}^{-2}$ ), 'Dashehari' (12.33 to $11.12 \mathrm{Kg} \mathrm{cm}^{-2}$ ) and 'Langra' $\left(12.17\right.$ to3.97 $\left.\mathrm{Kg} \mathrm{cm}^{-2}\right)$ from the day of harvest to $4^{\text {th }}$ day of storage indicating ripening of fruits. The decrease in firmness may be due to rapid loss of cell structure, due to evapo-transpiration and water loss leading to ripening of fruits. As the ripening stages advanced, fruit softening increased in 'Samar Bahisht Chaunsa' mangoes (Razzaq Kashif et al., 2013). Breakdown of cell wall polymers occurs during fruit ripening resulting in softening of mango fruits (Zaharah and Singh, 2011). Firmness is affected by cell wall modification and polygalacturonase and pectin methyl esterase degradation activity increases during ripening (Gonzalez-Aguilar et al., 2008). Similar reports on decreased firmness of 'Ataulfo' mango fruit was reported (Robles-Sanchez et al., 2009b). The TSS and TA varied significantly $(p \leq 0.5)$ with the increase in storage period and among the varieties (Fig.4.C and D). The TSS of fruits increased, while TA decreased with the increase in storage period and ripening of fruits. At the time of harvest, TSS was 8.87, 7.33 and $7.93{ }^{\circ} \mathrm{B}$ in cultivar 'Bombay Green', 'Dashehari' and 'Langra', respectively. TA at the time of harvest was 1.45, 0.80 and 1.49\% in cultivar 'Bombay Green', 'Dashehari' and 'Langra', respectively. TSS was highest $18.17^{\circ} \mathrm{B}$ and $0.28 \%$ acidity in cultivar 'Bombay Green' on the $8^{\text {th }}$ day of storage. In 'Dashehari' TSS was maximum $18.33^{\circ} \mathrm{B}$ and minimum $\mathrm{TA} \%$ on the $6^{\text {th }}$ day of storage indicating ripening of fruits. In 'Langra', TSS was maximum ( $18.27^{\circ} \mathrm{B}$ ) with minimum TA of $0.57 \%$ on the $6^{\text {th }}$ day of storage indicating ripening and senescence of fruits. During ripening of mango cv. 'Cogshall'; sugar content increased and tritratable acidity decreased (Jacques et al., 2009). During ripening, increase in TSS is attributed to free sugars accumulation from hydrolysis of starch (White, 2002). The mesocarp carotenoid content varied significantly $(p \leq 0.5)$ among the cultivars and the storage period of fruits (Fig.4.E.) With the increase in storage period, the carotenoids content of mesocarp increased indicating ripening and development of quality fruits for table purpose. The total carotenoid content of mesocarp

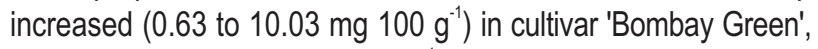
followed by ( 0.65 to $7.36 \mathrm{mg}^{\left.100 \mathrm{~g}^{-1}\right)}$ 'Dashehari' and it was $(0.23$ to $5.18 \mathrm{mg} 100 \mathrm{~g}^{-1}$ ) 'Langra' from the day of harvest to $8^{\text {th }}$ day of 

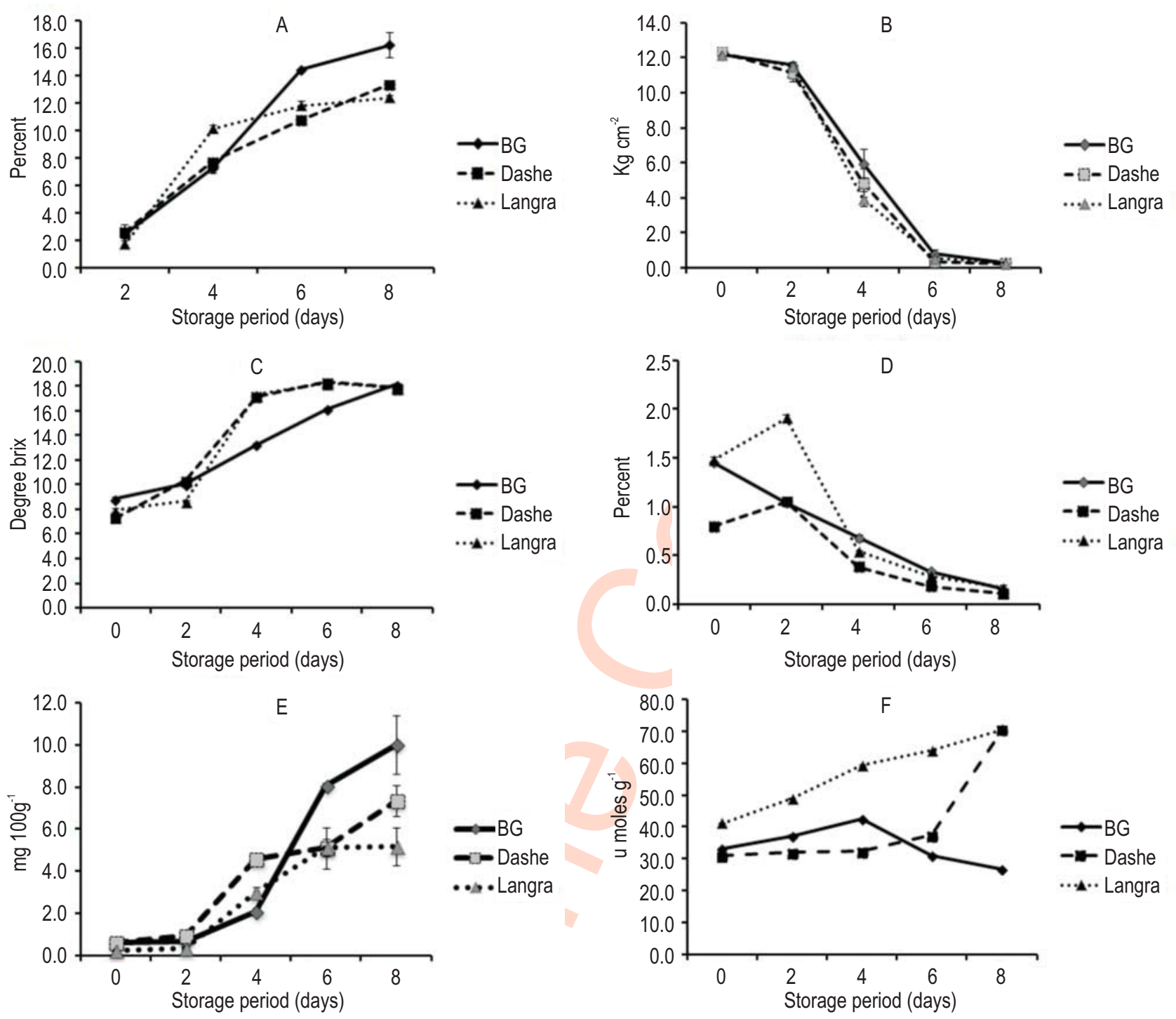

Fig. 4 : Changes in CPLW 'A', Firmness 'B', TSS 'C', titratable acidity 'D', total carotenoids of pulp 'E' and antioxidants 'F' of mango fruits in cultivars 'Bombay Green' (BG), 'Dashehari'(Dashe..) and 'Langra' during storage and ripening

storage. Increase in carotenoid biosynthesis in mango varieties is associated with the increase in respiration which is ethylene dependant (Saltveit, 1999).

Antioxidant capacity of mango varies according to cultivars, pre-harvest factors and post harvest technology including storage and ripening. Differences in the content of total carotenoids reported above could contribute to the difference in antioxidant activity among the varieties. The extracts from three mango varieties had significantly different values $(p<0.05)$ of FRAP activity (Fig. 4F). The total antioxidant was maximum in cultivar 'Langra' followed by 'Dashehari' and 'Bombay Green' on the $8^{\text {th }}$ day of storage. The antioxidant potential of mango varieties could be due to complicated bioactive compounds and its synergistic actions contributing to antioxidant activity in mango (Liu et al., 2013; Kevers et al.,2007; Kumar et al., 2016). The total antioxidant scavenging activity increased up to 7 day and later decreased in 'Chausa' variety (Razzaq et al., 2013).

From the present study it can be inferred that on the day of harvest mango fruits are firm, green colour of pericarp, become light green and then turn to yellowish green in colour. Proximal and distal end of mango fruits are correlated to pigment changes which is influenced by cultivars, fruit maturity and ripening conditions. Colour change in pericarp was not very distinct in cultivar 'Bombay Green' and 'Langra' while 'Dashehari' was 
yellow in colour. Mesocarp was yellow colour during storage and ripening in all the cultivars. Total carotenoids, antioxidants and TSS increases with decrease in firmness and TA during storage and ripening of fruits. It was speculated from the study that changes in pigmentation during storage and ripening in mango cultivars demonstrated variety specific behaviour.

\section{Acknowledgment}

The authors acknowledge the support and assistance from the Indian Council of Agricultural Research (ICAR) and Director ICAR-CISH, Lucknow.

\section{References}

Ahmed, J., U.S. Shivarr and K.S. Sandhu : Thermal degradation kinetics of carotenoids and visual colour of papaya puree. J. Food Sci., 67, 2692-2695 (2002).

Benzie, I.F.F. and J.J. Strain : The ferric reducing ability of plasma as a measure of "antioxidants power" the FRAP assay. Anal Biochem., 239, 70-76 (1996).

Chen, J.P., C.Y. Tai and B.H. Chen : Improved liquid chromatographic method for determination of carotenoids in Taiwanese mango (Mangifera indica L.). J. Chromatography A., 1054, 261-268 (2004).

Dhemre, J.K. and D.P. Waskar : Effect of postharvest fungicidal application on development of carotenoids pigments in Keasr mango fruits. Agric. Sci. Digest., 24, 27-29 (2004).

Fennema, O. R. : Food Chemistry. ${ }^{\text {rd }}$ Edn., Marcel Dekker Inc: New York (1996).

Gonzalez-Aguilar, G.A., J. Celis, R.R. Stotelo-Mundo, De La Rosa, J. Rodrigo-Garcia and E. Alvarez-Parrilla : Physiological and biochemical changes of different fresh cut mango cultivars stored at $5^{\circ} \mathrm{C}$. Int. J. Food Sci. Technol., 43, 91-101 (2008).

Jacques, J., C. Yanis and L. Mathieu : Comparison of postharvest changes in mango (cv. Cogshall) using a ripening class index (Rci) for different carbon supplies and harvest dates. Postharvest Biol. Technol., 54, 25-31(2009).

Janave, T. M. and A. Sharma : Inhibition of chlorophyll degradation in stay-green Langra mango (Mangifera indica L.) fruits. BARC News Letter, 273, 80-86 (2006).

Katy, A., C., T. K. Mc Ghie, A. White and A.B. Woolf : Skin colour and pigment changes during ripening of 'Hass' avocado fruit. Postharvest Biol. Technol., 31, 287-294 (2014).

Kevers, C., M. Falkowski, J. Jabart J. O. Defraigne, J. Dommes and J. Pincemail : Evolution of antioxidants capacity during storage of selected fruits and vegetables. J .Agric. Food. Chem., 55, 85968603 (2007).

Kumar, S., R. Kumar and V.E. Nambie : Effect of pectin methylesterase and $\mathrm{Ca}^{2+}$ ion treatments on antioxidant capacity, shelf-life and quality of minimally processed pomegranate (Punica granatum L.) arils. J. Environ. Biol., 37,193-199 (2016).

Lancaster, J. E., C.E. Lister, P.F. Reay and C. M. Triggs : Influence of pigment composition in skin colour in a wide range of fruits and vegetables. J. Am. Soc. Hort. Sci., 122, 594-598(1997).

Leonadi, C., A. Bailie and S. Guichard : Effects of fruit characteristic and climactic conditions on tomato transpiration in greenhouse. J. Hortic. Sci. Biotech., 74, 748-756 (1999).

Liu, Feng-Xia, Shu Fang Fu, Xiu-Fang Bi, Fang Chen, Xiao-Jun Liao,
Xiao-Seng Hu and Ji-Hong Wu : Physico-chemical and antioxidant properties of four mango (Mangifera indica L.) cultivars in China. Food Chemistry. 138, 396-405 (2013).

Lizada, M. C.: Postharvest physiology of mango-A review. Acta Hort., 291, 437-453 (1991).

Mercadante, A. Z., D. B. Rodriguez-Amaya and G. Britton : HPLC and mass spectrometric analysis of carotenoids from mango. $\mathrm{J}$. Agricul. Food Chem.., 53, 2211-2223(1997).

Pott, Breithaupt, D. E. and R. Carle : Detection of unusual carotenoids esters in fresh mango (Mangifera indica L.) cv. 'Kent'. Phytochemistry, 64, 825-829 (2003).

Ranganna, S.: Hand Book of analysis and quality control for fruits and vegetables products. Second edn. Tata Mc Grate Hill Publication Co. Ltd., New Delhi (2000).

Razzaq, K., A.S. Khan, A.U. Malik and M. Sahid : Ripening period influences fruit softening and antioxidative system of 'Samar Bahisht Chaunsa' mango. Scientia Horticulturae, 160,108-114 (2013).

Robles-Sanchez, R. M., M. A. Rojas-Grati, I. Odriozola-Serrano, G.A. Gonzale-Anguilar and O. Martin-Belloso : Effect of minimal processing on biotic compounds and antioxidant activity of freshcut 'Kent' mango (Mangifera indica L.). Postharvest Biol. Technol., 51, 384-390 (2009).

Robles-Sanchez, R.M., M.A. Islas-Osuna, H. Astiazaran-Garria, F.A. Vazquez-Ortiz, O. Martin Belloso, S. Gorinstein, G.A. GonzalezAugilar: Quality index consumer acceptability, bioactive compounds and antioxidant activity of fresh cut 'Ataulfo' mangoes (Mangifera indica $\mathrm{L}$ ) as affected by low temperature storage. J. Food Sci., 74, S126-S134 (2009b).

Saltveit, M.E.: Effect of ethylene on quality of fresh fruits and vegetables. Postharv. Biol. Technol., 15, 279-292 (1999).

Saxsena, P., V.K. Singh and N. Pathak: Antioxidative enzymez and biochemical changes in paclobutrazole induced flowering in mango (M.indica) cultivars. J. Environ. Biol., 35, 1061-1066 (2014).

Singh, P., M.K. Singh, V. Kumar, M. Kumar and S. Malik : Effect of physico-chemical treatment on ripening behaviour and postharvest quality of Amrapali mango (Mangifera indica L.) during storage. J. Environ. Biol.., 33, 227-232 (2012).

Valente, A., T.G. Albuquerque, A. Sanches-Silva and H.S. Costa : Ascorbic acid content in exotic fruits: A contribution to produce quality data for food composition database. Food Res. Int., 34, 705-714 (2011).

Vasquez-Caicedo, A.L., P. Sruamsiri, R. Carle and S. Neidhart : Accumulation of all trans- $\beta$-carotene and its 9-cis and 13-cis stereoisomers during postharvest ripening of nine Thai mango cultivars. J. Agricul. Food Chem., 53, 4827-4835 (2005).

Vasquez-Caicedo, A.L., S. Schilling, R. Carle and S. Neidhart : Impact of packaging and storage condition on colour and $\beta$-carotene retention of pasteurised mango puree. Eur. Food Res. Technol., 224, 581-590 (2007).

White P.J.: Recent advances in fruit development and ripening: An overview. J. Exp. Bot., 53, 1995 (2002).

Wills, R.B.H., Mc W.B. Glasson, D. Graham, T.H. Lee and E.G. Hall : Postharvest. An Introduction to the Physiology and Handling of Fruits and Vegetables. Van Nostrand Reinhold, New York, p. 174 (1989).

Zaharah, S.S. and Z. Singh : Mode of action of nitric oxide in inhibiting ethylene biosynthesis and fruit softening during ripening and cold storage of 'Kensington Pride' mango. Postharvest Biol. Technol., 62, 258-266 (2011). 